\title{
SECOND LAW ANALYSIS OF FLOW, HEAT AND MASS TRANSFER PAST A NONLINEARLY STRETCHING PERMEABLE WEDGE WITH TEMPERATURE JUMP AND CHEMICAL REACTION
}

\begin{abstract}
Second law analysis (entropy generation) for the steady two-dimensional laminar forced convection flow, heat and mass transfer of an incompressible viscous fluid past a nonlinearly stretching porous (permeable) wedge is numerically studied. The effects of viscous dissipation, temperature jump, and first-order chemical reaction on the flow over the wedge are also considered. The governing boundary layer equations for mass, momentum, energy and concentration are transformed using suitable similarity transformations to three nonlinear ordinary differential equations (ODEs). Then, the ODEs are solved by using a Keller's box algorithm. The effects of various controlling parameters such as wedge angle parameter, velocity ratio parameter, suction/injection parameter, Prandtl number, Eckert number, temperature jump parameter, Schmidt number, and reaction rate parameter on dimensionless velocity, temperature, concentration, entropy generation number, and Bejan number are shown in graphs and analyzed. The results reveal that the entropy generation number increases with the increase of wedge angle parameter, while it decreases with the increase of velocity ratio parameter. Also, in order to validate the obtained numerical results of the present work, comparisons are made with the available results in the literature as special cases, and the results are found to be in a very good agreement.
\end{abstract}

\section{Nomenclature}

$a-$ coefficient of fluid velocity outside boundary layer $\left(\mathrm{m}^{1-n} \mathrm{~s}^{-1}\right)$

$c$ - stretching rate of the wedge $\left(\mathrm{m}^{1-n} \mathrm{~s}^{-1}\right)$

Be - Bejan number $(-)$

$\mathrm{Br}-$ Brinkman number $\left(=\mu u_{w}^{2}(x) /(k \Delta T)\right)(-)$

$C$ - concentration (-)

$C_{w}$ - concentration at the wedge surface (-)

\footnotetext{
${ }^{1}$ Department of Mechanical Engineering, Salmas Branch, Islamic Azad University, Salmas, Iran.
} Email:dalir@aut.ac.ir 
$C_{\infty} \quad$ - concentration far away from the wedge (-)

$\Delta C \quad$ - concentration difference $\left(=C_{w}-C_{\infty}\right)(-)$

$C_{f, x} \quad-$ local skin friction coefficient $\left(=f^{\prime \prime}(0) \sqrt{(n+1) / 2 \mathrm{Re}_{x}}\right)(-)$

$C_{P} \quad$ - specific heat at constant pressure $\left(\mathrm{J} \mathrm{kg}^{-1} \mathrm{~K}^{-1}\right)$

$D$ - concentration diffusion coefficient $\left(\mathrm{m}^{2} \mathrm{~s}^{-1}\right)$

Ec $\quad-$ Eckert number $\left(=u_{w}^{2}(x) / C_{P}\left(T_{w}-T_{\infty}\right)\right)(-)$

$f \quad-$ dimensionless stream-function $\left(=\psi(x, y) \sqrt{(n+1) /\left(2 v x u_{w}\right)}\right)(-)$

$f^{\prime} \quad-$ dimensionless velocity variable $\left(=u / u_{w}(x)\right)(-)$

$k \quad-$ thermal conductivity $\left(\mathrm{W} \mathrm{m}^{-1} \mathrm{~K}^{-1}\right)$

$l_{1} \quad-$ temperature jump coefficient $\left(\mathrm{m}^{-1}\right)$

$n \quad-$ exponent of stretching velocity of the wedge $(-)$

$\mathrm{Nu}_{x} \quad-$ local Nusselt number $\left(=-\theta^{\prime}(0) \sqrt{(n+1) \mathrm{Re}_{x} / 2}\right)(-)$

$N_{s} \quad$ - entropy generation number (-)

$\left(N_{s}\right)_{t h}$ - entropy generation due to heat transfer (-)

$N_{f r} \quad$ - entropy generation due to fluid friction (-)

$N_{\text {dif }} \quad-$ entropy generation due to mass transfer (-)

Pr $\quad-$ Prandtl number $(=v / a)(-)$

$R \quad-$ universal constant of gases $\left(\mathrm{J} \mathrm{m}^{-3} \mathrm{~K}^{-1}\right)$

$\operatorname{Re}_{x} \quad$ - local Reynolds number $\left(=u_{w}(x) x / v\right)(-)$

$S_{\text {gen }} \quad-$ local volumetric rate of entropy generation $\left(\mathrm{W} \mathrm{m}^{-3} \mathrm{~K}^{-1}\right)$

$\left(S_{g e n}\right)_{0}$ - characteristic entropy generation rate $\left(=k(\Delta T)^{2} /\left(x^{2} T_{\infty}^{2}\right)\right)\left(\mathrm{W} \mathrm{m}^{-3} \mathrm{~K}^{-1}\right)$

Sc $\quad-$ Schmidt number $(=v / D)(-)$

$\mathrm{Sh}_{x} \quad$ - local Sherwood number $\left(=-\phi^{\prime}(0) \sqrt{(n+1) \mathrm{Re}_{x} / 2}\right)(-)$

$T \quad$ - temperature variable (K)

$T_{w} \quad-$ uniform temperature of the wedge $(\mathrm{K})$

$T_{\infty} \quad$ - temperature of fluid far away from the wedge $(\mathrm{K})$

$\Delta T \quad$ - temperature difference $\left(=T_{w}-T_{\infty}\right)(\mathrm{K})$

$u \quad$ - velocity in $x$-direction $\left(\mathrm{m} \mathrm{s}^{-1}\right)$

$u_{w} \quad-$ stretching velocity of the wedge $\left(\mathrm{m} \mathrm{s}^{-1}\right)$

$U_{\infty} \quad$ - fluid velocity outside the boundary layer $\left(\mathrm{m} \mathrm{s}^{-1}\right)$

$v \quad-$ velocity in $y$-direction $\left(\mathrm{m} \mathrm{s}^{-1}\right)$

$v_{w} \quad-$ suction/injection velocity along $y$-axis

$x \quad-x$-axis aligned along the stretching wedge (m)

$y-y$-axis aligned normal to the stretching wedge $(\mathrm{m})$

\section{Greek symbols}

$\alpha \quad-$ thermal diffusivity $\left(\mathrm{m}^{2} \mathrm{~s}^{-1}\right)$

$\beta \quad$ - wedge angle parameter $(=2 n /(n+1))(-)$

$\gamma \quad-$ chemical reaction rate parameter $\left(=2 \kappa x /\left[(n+1) u_{w}\right]\right)(-)$

$\varepsilon \quad-$ dimensionless constant parameter $\left(=\left(R D C_{\infty}\right) / k\right)(-)$

$\eta \quad-$ similarity variable $\left(=y \sqrt{(n+1) u_{w} /(2 v x)}\right)(-)$

$\theta \quad-$ dimensionless temperature variable $\left(=\left(T-T_{\infty}\right) /\left(T_{w}-T_{\infty}\right)\right)(-)$

$\lambda \quad-$ velocity ratio parameter $(=a / c)(-)$ 


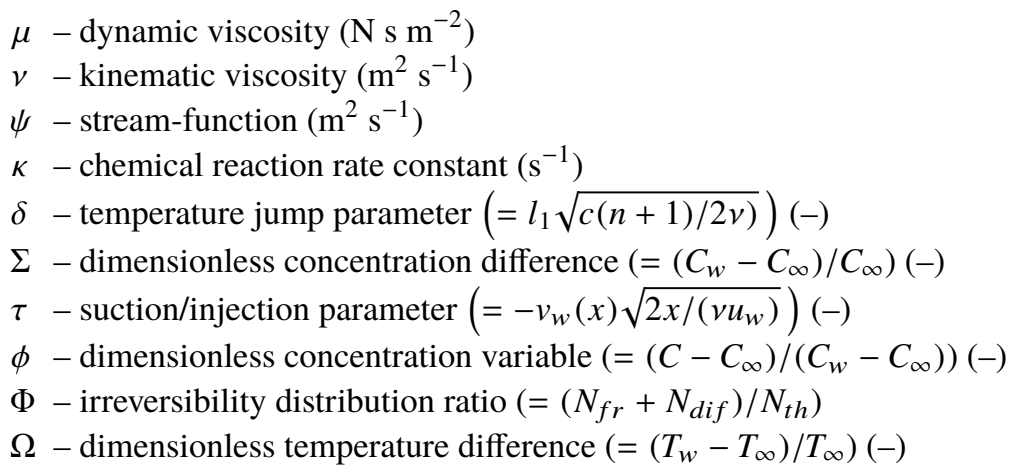

\section{Subspripts}

$\infty$ - infinity

$f$ - fluid

$w$ - wedge surface

\section{Introduction}

In recent years, a lot of interest has been focused on studying the problem of incompressible steady viscous flow over a non-isothermal wedge because of its wide practical applications in technological processes such as design for power generators, design for cooling of nuclear reactors, construction of heat exchangers, and blood flow measurement techniques [1]. Chamkha et al. [2] investigated the steady magneto-hydrodynamic (MHD) forced convective boundary layer flow of a Newtonian, electrically conducting and heat generating/absorbing fluid over a non-isothermal wedge in the presence of thermal radiation effects. They also included the effects of viscous dissipation, Joule heating and stress work, and solved the obtained non-similar equations by an implicit iterative tri-diagonal finite difference method. Pal and Mondal [3] carried out an analysis to study the heat transfer characteristics of an incompressible Newtonian and heat generating/absorbing fluid having temperature dependent viscosity over a non-isothermal wedge in the presence of thermal radiation. They used the Rosseland approximation to describe the radiative heat flux in the energy equation and assumed the wedge surface to be permeable so as to allow for possible wall suction or injection. They numerically solved the governing equations of the problem by applying a fifth order RungeKutta-Fehlberg scheme with shooting technique and presented the results for the velocity and temperature profiles for a prescribed magnetic field parameter. Zheng et al. [4] investigated MHD flow and heat transfer over a porous shrinking sheet with velocity slip and temperature jump. They proposed a new technique to improve the computation efficiency of the homotopy analysis method (HAM), and also obtained closed form expressions for the two dimensional flow. Rahman et al. [5] studied the effects of thermophoresis particle deposition on an unsteady two dimensional forced convection heat and mass transfer flow past a wedge taking into account the 
variation of fluid viscosity and fluid Prandtl number with temperature. They solved the local similarity equations using Nachtsheim-Swigert shooting iteration technique along with the sixth order Runge-Kutta integration scheme. They showed that in modeling the thermal boundary-layer flow with a temperature-dependent viscosity, the Prandtl number must be treated as a variable rather than a constant within the boundary layer. Bararnia et al. [6] studied the temperature and velocity fields associated with the Falkner-Skan boundary layer problem. They analytically solved the nonlinear boundary layer equations by homotopy Perturbation method (HPM) employing Pade technique. Muhaimin et al. [7] presented an analysis to investigate the effect of thermophoresis particle deposition and temperature dependent viscosity on unsteady MHD mixed convective heat and mass transfer of a viscous incompressible electrically conducting fluid past a porous wedge in the presence of chemical reaction. They carried out numerical calculations for different values of dimensionless parameters in the problem and found that the flow field is influenced appreciably by the applied magnetic field and thermophoresis particle deposition. Rahman et al. [8] investigated the effects of thermophoresis on an unsteady MHD forced convective heat and mass transfer flow of an incompressible electrically conducting fluid over a wedge with variable electric conductivity. They numerically solved the governing locally similar ordinary differential equations by applying Nachtsheim-Swigert shooting iteration technique along with sixth order RungeKutta integration scheme. They found that the friction coefficient, Nusselt number and Sherwood number are higher for the fluids of constant electric conductivity than those of the variable electric conductivity. Prasad et al. [9] obtained numerical solutions for the MHD mixed convection boundary layer flow of an electrically conducting fluid over a non-isothermal wedge in presence of variable thermal conductivity, viscous dissipation, heat generation/absorption, thermal radiation, Joule heating and stress work. They numerically solved the governing partial differential equations by using an efficient finite difference scheme, and revealed that the flow field is influenced appreciably by the applied magnetic field in addition to the other parameters. Muhaimin et al. [10] presented an analysis to investigate the effect of thermophoresis particle deposition and temperature dependent viscosity on unsteady non-Darcy MHD mixed convective heat and mass transfer of an electrically conducting fluid past a porous wedge in the presence of chemical reaction. They indicated that the flow field is influenced by the magnetic field and thermophoresis particle deposition. Pal and Mondal [11] studied the thermophoresis particle deposition and Soret-Dufour effects on the convective flow, heat transfer and mass transfer characteristics of an incompressible electrically conducting fluid having temperature dependent viscosity over a non-isothermal wedge in the presence of thermal radiation. They numerically solved the transformed coupled nonlinear ordinary differential equations, and found that the skin friction coefficient and the local Sherwood number enhance with an increase in the values of thermal radiation parameter. Ganapathirao et al. [12] studied the effect of non-uniform single and double slot suction/injection on an unsteady mixed convection boundary layer 
flow over a vertical wedge with chemical reaction and heat generation/absorption. They obtained non-similar solutions by using quasi-linearization technique in combination with an implicit finite difference scheme, and indicated that the skin friction, heat and mass transfer coefficients increase with non-uniform slot suction.

All the researchers mentioned above restricted their investigations to the flow and heat transfer of regular fluid (common fluid) over a wedge. However, the role of nanofluid (regular fluid containing nanoparticles) on the flow and heat transfer processes is of major significance in the design of many advanced energy conversion systems. Rahman et al. [13] investigated the heat transfer characteristics of a two-dimensional steady MHD slip flow of water based nanofluids $\left(\mathrm{TiO}_{2}\right.$-water, $\mathrm{Al}_{2} \mathrm{O}_{3}$-water, and $\mathrm{Cu}$-water) over a wedge with convective surface taking into account the effects of heat generation/absorption. They obtained the local similarity solutions, and showed that the rate of shear stress is significantly influenced by the surface convection parameter and the slip parameter. Kandasamy et al. [14] investigated theoretically the unsteady Hiemenz flow of an incompressible viscous $\mathrm{Cu}$-water nanofluid past a porous wedge due to solar energy (incidental radiation). Using a special form of Lie symmetry group transformations, they transformed the govering partial differential equations of the problem into a system of ordinary differential equations and numerically solved them using a Runge-Kutta-Gill based shooting method. They concluded that the flow field and temperature are significantly influenced by incidental radiation, thermal stratification, buoyancy force and porosity of the wedge. Zheng et al. [15] investigated the flow and radiation heat transfer of a nanofluid over a stretching sheet with velocity slip and temperature jump in a porous medium. They solved the governing coupled differential equations both numerically and analytically by local similarity method, and graphically presented the effects of involved parameters on the velocity, temperature and concentration profiles. Kandasamy et al. [16] investigated theoretically the effect of copper nanoparticles in the presence of magnetic field on an unsteady non-Darcy flow and heat transfer of incompressible copper-water nanofluid along a porous wedge due to solar energy.

In the last decade, the entropy generation for various flows has also been analyzed by many researchers. For example, Aiboud and Saouli [17] presented an entropy generation analysis for viscoelastic MHD flow over a stretching surface. They analytically obtained the velocity and temperature profiles using Kummer's functions and computed the entropy generation number. They discussed the influences of the heat source/sink parameter, the Hartmann number, the dimensionless group parameter and the Reynolds number on the entropy generation. In a paper, Makinde [18] studied the entropy generation in MHD flow and heat transfer over a plate with a convective surface boundary condition. Hedayati et al. [19] employed entropy generation minimization (EGM) technique to optimize fluid flow and heat transfer over a moving wedge. They indicated that as the slope of the wedge increased, the absolute values of the optimum moving wedge parameter grew as 
well. Dalir [20] numerically investigated the entropy generation for steady flow and heat transfer of a Jeffrey fluid over a linearly stretching sheet. He transformed the governing equations to two nonlinear coupled ordinary differential equations and solved them by applying a numerical implicit Keller's box method. He showed that the entropy generation number increased with the increase of Deborah number. Dalir et al. [21] studied entropy generation for steady two dimensional forced convection MHD flow, heat and mass transfer of a non-Newtonian nanofluid over a linearly stretching sheet. They numerically solved the governing equations and examined the influence of various controlling parameters on the entropy generation characteristics. Thus, by more literature survey, it is revealed that, until now, the entropy analysis has not been investigated for the fluid flow, heat transfer and mass transfer over a nonlinearly stretching permeable wedge.

In the present paper, entropy generation for the forced convection flow, heat and mass transfer over a stretching permeable non-isothermal wedge is investigated. Moreover, the effects of viscous dissipation and first-order chemical reaction are included. To the best of the author's knowledge, so far in no paper in the literature, entropy generation for flow over a nonlinearly stretching permeable non-isothermal wedge with chemical reaction has been studied. The governing coupled, nonlinear differential equations for the flow, heat and mass transfer are numerically solved by an implicit finite difference scheme known as Keller's box method. The influences of various controlling parameters including wedge angle parameter, temperature jump parameter, and Schmidt number on dimensionless velocity, temperature, concentration, entropy generation number, and Bejan number profiles are analyzed.

\section{Mathematical formulation}

A steady two dimensional laminar forced convection boundary layer flow, heat transfer and mass transfer of an incompressible viscous Newtonian fluid along a nonlinearly stretching permeable wedge in the presence of viscous dissipation is considered (see Fig. 1). Before the fluid begins to flow along the wedge, velocity, temperature and concentration of the fluid are uniform. This flow is called potential

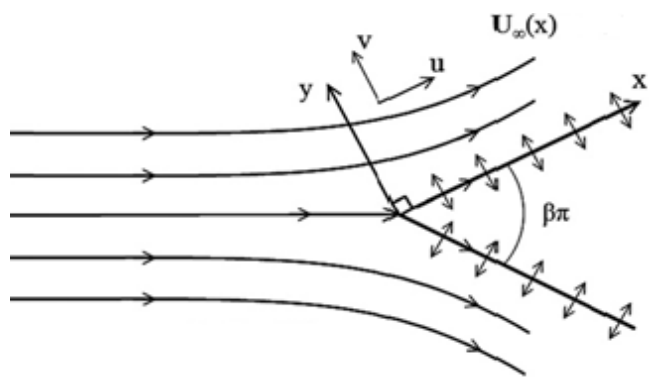

Fig. 1. The physical model and coordinate system [11] 
flow. When the viscous fluid reaches over the edge of the wedge, a boundary layer is formed on the wedge surface. Inside the boundary layer, the flow is influenced by the solid surface of the wedge and thus fluid properties, i.e. velocity, temperature, and concentration, vary from their potential flow values. However, outside the boundary layer, the flow is not influenced by the wedge solid surface, i.e. the fluid properties keep their free-stream or potential flow values for temperature and concentration. Nevertheless, the velocity of fluid outside the boundary layer is influenced by the shape of the wedge and therefore it varies nonlinearly by the distance along the wedge surface. Thus, for flow over a wedge, the velocity outside the boundary layer is considered to be directly proportional to a power of length measured along the wedge surface from the stagnation point (i.e. edge of the wedge). For the wedge flow, the similarity solutions also exist only when the velocity of potential flow varies nonlinearly with length along the wedge surface. A chemical reaction is also considered to occurs inside flow geometry. The chemical reaction can be taken into account by a difference in concentration of species inside the boundary layer and outside of it. It in fact indicates that a device or process is implanted in the flow geometry which could generate/absorb species. Another assumption is that the wedge is permeable such that the fluid suction/injection can occur at the wedge surface. In the case of injection, the fluid which is injected into the flow through the wedge surfaceis assumed to have a temperature and concentration equal to that of the fluid at the upper surface of the wedge. A temperature jump (thermal slip) condition is also assumed to exist at wedge surface. Due to this condition, the fluid temperature at the wedge surface is not constant; it is linearly proportional to the temperature gradient at the wedge surface. The $x$-axis is considered to be along the upper surface of the wedge in the flow direction, and the $y$-axis is considered to be perpendicular to $x$-axis. The governing partial differential equations of mass, momentum, energy and concentration conservations in accompany of a first-order chemical reaction are expressed as follows $[3,7,10]$ :

$$
\begin{gathered}
\frac{\partial u}{\partial x}+\frac{\partial v}{\partial y}=0, \\
u \frac{\partial u}{\partial x}+v \frac{\partial u}{\partial y}=U_{\infty} \frac{d U_{\infty}}{d x}+v\left(\frac{\partial^{2} u}{\partial x^{2}}+\frac{\partial^{2} u}{\partial y^{2}}\right), \\
u \frac{\partial T}{\partial x}+v \frac{\partial T}{\partial y}=\alpha\left(\frac{\partial^{2} T}{\partial x^{2}}+\frac{\partial^{2} T}{\partial y^{2}}\right)+\frac{v}{C_{p}}\left[\left(\frac{\partial u}{\partial x}\right)^{2}+\left(\frac{\partial u}{\partial y}\right)^{2}\right], \\
u \frac{\partial C}{\partial x}+v \frac{\partial C}{\partial y}=D\left(\frac{\partial^{2} C}{\partial x^{2}}+\frac{\partial^{2} C}{\partial y^{2}}\right)-\kappa\left(C-C_{\infty}\right),
\end{gathered}
$$

where $u$ and $v$ are the velocity components in $x$ and $y$ directions respectively, $U_{\infty}$ is the fluid velocity outside the boundary layer (free stream velocity), $v$ is the kinematic viscosity of the fluid, $T$ is the fluid temperature, $\alpha$ is the fluid 
thermal diffusivity, $C_{p}$ is the specific heat at constant pressure of the fluid, $C$ is the concentration field, $D$ is the concentration diffusion coefficient, and $\kappa$ is the chemical reaction rate constant. The boundary conditions for system of Eqs. (1)-(4) are written as follows $[4,15,19]$ :

$$
\begin{gathered}
u=u_{w}(x)=c x^{n}, \quad v=v_{w}(x), \quad T=T_{w}+l_{1} \frac{\partial T}{\partial y}, \quad C=C_{w} \text { at } y=0, \\
u=U_{\infty}(x)=a x^{n}, \quad T \rightarrow T_{\infty}, \quad C \rightarrow C_{\infty} \text { as } y \rightarrow \infty,
\end{gathered}
$$

where $u_{w}$ is the stretching velocity of the wedge, $v_{w}$ is the suction/injection velocity through the wedge, $T_{w}$ and $C_{w}$ are the temperature and concentration at the wedge surface respectively, $T_{\infty}$ and $C_{\infty}$ are the temperature and concentration far away from the wedge respectively, and $c, a, l_{1}$, and $n$ are positive constants. In order to non-dimensionalize the governing equations (1)-(4) and boundary conditions of Eq. (5), the similarity transformations including the similarity variable $\eta$, dimensionless stream-function $f$, dimensionless velocity variable $f^{\prime}$, dimensionless temperature variable $\theta$, and dimensionless concentration variable $\phi$ are introduced as follows [22]:

$$
\begin{gathered}
\eta=y \sqrt{\frac{(n+1) u_{w}(x)}{2 v x}}, \quad f(\eta)=\psi(x, y) \sqrt{\frac{n+1}{2 v x u_{w}(x)}}, \\
f^{\prime}(\eta)=\frac{u}{u_{w}(x)}, \quad \theta(\eta)=\frac{T-T_{\infty}}{T_{w}-T_{\infty}}, \quad \phi(\eta)=\frac{C-C_{\infty}}{C_{w}-C_{\infty}} .
\end{gathered}
$$

By inserting the similarity transformations of Eq. (6) into Eqs. (1)-(5), the transformed equations and boundary conditions are obtained as:

$$
\begin{gathered}
f^{\prime \prime \prime}+f f^{\prime \prime}+\beta\left(\lambda^{2}-f^{2}\right)=0, \\
\theta^{\prime \prime}+\operatorname{Pr}\left(f \theta^{\prime}+\operatorname{Ec} f^{\prime \prime 2}\right)=0, \\
\phi^{\prime \prime}+\operatorname{Sc} f \phi^{\prime}-\operatorname{Sc} \gamma \phi=0, \\
f(0)=\tau, \quad f^{\prime}(0)=1, \quad f^{\prime}(\infty)=\lambda, \\
\theta(0)=1+\delta \theta^{\prime}(0), \quad \theta(\infty)=0, \\
\phi(0)=1, \quad \phi(\infty)=0,
\end{gathered}
$$

where $\beta, \lambda, \tau, \operatorname{Pr}, \mathrm{Ec}, \delta, \mathrm{Sc}$, and $\gamma$ are wedge angle parameter (that corresponds to $\omega=\beta \pi$ for a total angle $\omega$ of the wedge), velocity ratio parameter (that represents the ratio of free stream velocity to the wedge stretching velocity), suction/injection 
parameter, Prandtl number, Eckert number, temperature jump parameter, Schmidt number, and reaction rate parameter respectively, which are defined as [19]:

$$
\begin{gathered}
\beta=\frac{2 n}{(n+1)}, \quad \lambda=\frac{a}{c}, \quad \tau=-v_{w}(x) \sqrt{\frac{2 x}{v u_{w}}}, \quad \operatorname{Pr}=\frac{v}{\alpha}, \\
\mathrm{Ec}=\frac{u_{w}^{2}}{C_{p}\left(T_{w}-T_{\infty}\right)}, \quad \delta=l_{1} \sqrt{\frac{c(n+1)}{2 v}}, \quad \mathrm{Sc}=\frac{v}{D}, \quad \gamma=\frac{2 \kappa x}{(n+1) u_{w}} .
\end{gathered}
$$

The parameters of engineering interest are the local skin friction coefficient $\left(C_{f, x}\right)$, the local Nusselt number $\left(\mathrm{Nu}_{x}\right)$ and the local Sherwood number $\left(\mathrm{Sh}_{x}\right)$, which are given by [19]:

$$
\begin{gathered}
C_{f, x}=f^{\prime \prime}(0) \sqrt{\frac{(n+1)}{2 \operatorname{Re}_{x}}}, \quad \mathrm{Nu}_{x}=-\theta^{\prime}(0) \sqrt{\frac{n+1}{2} \operatorname{Re}_{x},} \\
\operatorname{Sh}_{x}=-\phi^{\prime}(0) \sqrt{\frac{n+1}{2} \operatorname{Re}_{x}},
\end{gathered}
$$

where $\operatorname{Re}=u_{w} x / v$ is the local Reynolds number.

\section{Entropy generation analysis}

The local volumetric rate of entropy generation, $S_{\text {gen }}\left(\mathrm{W} / \mathrm{m}^{3} \mathrm{~K}\right)$, in the presence of viscous dissipation, heat transfer and mass transfer is given by [23-25]:

$$
S_{\text {gen }}=\frac{k}{T_{\infty}^{2}}\left(\frac{\partial T}{\partial y}\right)^{2}+\frac{\mu}{T_{\infty}}\left(\frac{\partial u}{\partial y}\right)^{2}+\frac{R D}{C_{\infty}}\left(\frac{\partial C}{\partial y}\right)^{2}+\frac{R D}{T_{\infty}}\left(\frac{\partial T}{\partial y}\right)\left(\frac{\partial C}{\partial y}\right),
$$

where $k, \mu$, and $R$ are the fluid thermal conductivity, fluid dynamic viscosity, and universal constant of gases, respectively. The first term on the right-hand side of Eq. (13) is due to heat transfer, the second term is due to fluid friction, and the third and fourth terms are due to mass transfer. A characteristic entropy generation rate $\left(S_{g e n}\right)_{0}$ is defined as [20]:

$$
\left(S_{g e n}\right)_{0}=\frac{k}{T_{\infty}^{2}} \frac{(\Delta T)^{2}}{x^{2}} .
$$

By using Eqs. (13)-(14) and similarity transformations of Eq. (6), the dimensionless entropy generation number $N_{S}$ can be expressed as follows [21]:

$$
N_{s}=\frac{S_{\text {gen }}}{\left(S_{\text {gen }}\right)_{0}}=\operatorname{Re} \theta^{\prime 2}+\frac{\operatorname{Br} \operatorname{Re}}{\Omega} f^{\prime \prime 2}+\frac{\operatorname{Re} \varepsilon \Sigma^{2}}{\Omega^{2}} \phi^{\prime 2}+\frac{\operatorname{Re} \varepsilon \Sigma}{\Omega} \theta^{\prime} \phi^{\prime},
$$


where $\operatorname{Re}, \mathrm{Br}, \Omega, \Sigma, \varepsilon$ are the Reynolds number, Brinkman number, dimensionless temperature difference, dimensionless concentration difference, and the dimensionless constant parameter respectively, which are represented as:

$$
\operatorname{Re}=\frac{u_{w} x}{v}, \quad \mathrm{Br}=\frac{\mu\left(u_{w}\right)^{2}}{k \Delta T}, \quad \Omega=\frac{\Delta T}{T_{\infty}}, \quad \Sigma=\frac{\Delta C}{C_{\infty}}, \quad \varepsilon=\frac{R D C_{\infty}}{k},
$$

where $\Delta T=T_{w}-T_{\infty}, \Delta C=C_{w}-C_{\infty}$. We assign $N_{t h}$ to the first term in Eq. (15) due to heat transfer (thermal diffusion), $N_{f r}$ to the second term due to fluid friction (viscous dissipation), and $N_{d i f}$ to the third and fourth terms due to the mass transfer (concentration diffusion), such that:

$$
N_{t h}=\operatorname{Re} \theta^{\prime 2}, \quad N_{f r}=\frac{\operatorname{Br} \operatorname{Re}}{\Omega} f^{\prime \prime 2}, \quad N_{d i f}=\frac{\operatorname{Re} \varepsilon \Sigma^{2}}{\Omega^{2}} \phi^{\prime 2}+\frac{\operatorname{Re} \varepsilon \Sigma}{\Omega} \theta^{\prime} \phi^{\prime} .
$$

The irreversibility distribution ratio is then given as $\Phi=\left(N_{f r}+N_{d i f}\right) / N_{t h}$. Therefore, whenever $0 \leq \Phi<1$, the heat transfer irreversibility dominates. The irreversibility due to the fluid friction with mass transfer dominates when $\Phi>1$. The contribution of both heat transfer and fluid friction with mass transfer to entropy generation are equal when $\Phi=1$. However, in many engineering designs and energy optimization problems, the contribution of heat transfer to entropy generation $\left(N_{t h}\right)$ and fluid friction and mass transfer effects $\left(N_{f r}+N_{d i f}\right)$ to overall local entropy generation $\left(N_{s}=N_{t h}+N_{f r}+N_{d i f}\right)$ is needed. In order to achieve this, the Bejan number Be is defined as follows:

$$
\mathrm{Be}=\frac{N_{t h}}{N_{s}}=\frac{N_{t h}}{N_{t h}+N_{f r}+N_{d i f}}=\frac{1}{1+\Phi}
$$

From Eq. (18), it is obvious that $0 \leq \mathrm{Be}<1$. The zero value of the Bejan number corresponds to the limit where the irreversibility is dominated by the combined effects of fluid friction and mass transfer, while $\mathrm{Be}=1$ is the limit where the irreversibility due to heat transfer by virtue of finite temperature differences dominates the flow system. When $\mathrm{Be}=1 / 2$, the contributions of both factors to entropy generation are equal.

\section{Method of solution}

The system of three nonlinear coupled ODEs (7)-(9) with the boundary conditions of Eq. (10) were solved using a finite-difference implicit numerical scheme known as the Keller's box method. The method is comprised of the following steps [26]:

1. ODEs (7)-(9) are transformed to a system of eight first-order ODEs.

2. By using central differences, the first order ODEs are altered to difference equations. 
3. Using Newton's method of linearization, the nonlinear difference equations are linearized.

4. The linearized difference equations are solved by an implicit tri-diagonal elimination technique.

\section{Results and discussion}

Steady two dimensional laminar forced convective flow, heat and mass transfer of an incompressible viscous fluid past a nonlinearly stretching porous wedge with temperature jump and chemical reaction is considered and entropy generation is investigated. The governing differential equations are solved by using a Keller's box numerical algorithm. Table 1 shows the comparisons of numerical values of $f^{\prime \prime}(0)$ for different amounts of velocity ratio parameter $\lambda$, when $\beta=1.0, \tau=0.0$. A very good agreement (within relative error of $0.01 \%$ ) between the results of present work with those of Ibrahim et al. [27] and Jalilpour et al. [28] is observed. For various values of $\lambda$, Table 2 compares the numerical values for $-\theta^{\prime}(0)$ between present work and Ibrahim et al. [27] when $\beta=1.0, \tau=0.0, \operatorname{Pr}=1.0, \mathrm{Ec}=0.0$, $\delta=0.0$, in which a good agreement is again observed.

Table 1.

Comparison of numerical values for $f^{\prime \prime}(0)$ when $\beta=1.0, \tau=0.0$

\begin{tabular}{|c|c|c|c|}
\hline$\lambda$ & $\begin{array}{c}\text { Present work } \\
f^{\prime \prime}(0)\end{array}$ & $\begin{array}{c}\text { Ibrahim et al. [27] } \\
f^{\prime \prime}(0)\end{array}$ & $\begin{array}{c}\text { Jalilpour et al. [28] } \\
f^{\prime \prime}(0)\end{array}$ \\
\hline 0.1 & -0.969395 & -0.9694 & -0.969387 \\
\hline 0.2 & -0.918127 & -0.9181 & -0.918164 \\
\hline 0.5 & -0.667308 & -0.6673 & -0.667269 \\
\hline 2.0 & 2.018202 & 2.0175 & 2.017591 \\
\hline 3.0 & 4.731851 & 4.7292 & 4.727521 \\
\hline
\end{tabular}

Table 2 .

Comparison of numerical values for $-\theta^{\prime}(0)$ when $\beta=1.0, \tau=0.0, \operatorname{Pr}=1.0, \mathrm{Ec}=0.0, \delta=0.0$

\begin{tabular}{|c|c|c|}
\hline$\lambda$ & $\begin{array}{c}\text { Present work } \\
-\theta^{\prime}(0)\end{array}$ & $\begin{array}{c}\text { Ibrahim et al. [27] } \\
-\theta^{\prime}(0)\end{array}$ \\
\hline 0.1 & 0.602145 & 0.6022 \\
\hline 0.2 & 0.624464 & 0.6245 \\
\hline 0.5 & 0.692471 & 0.6924 \\
\hline
\end{tabular}

Fig. 2 demonstrates velocity profiles $f^{\prime}(\eta)$ for various values of wedge angle parameter $\beta$, suction/injection parameter $\tau$, and velocity ratio parameter $\lambda$. The velocity decreases by the increase of both wedge angle parameter $\beta$ and suction/injection parameter $\tau$, as it seen in Figs. 2 a and 2 b. However, it is seen in Fig. $2 c$ that $f^{\prime}(\eta)$ increases by an increase in the velocity ratio parameter $\lambda$.

Fig. 3 shows temperature profiles $\theta(\eta)$ for various values of wedge angle parameter $\beta$, suction/injection parameter $\tau$, velocity ratio parameter $\lambda$, Prandtl 


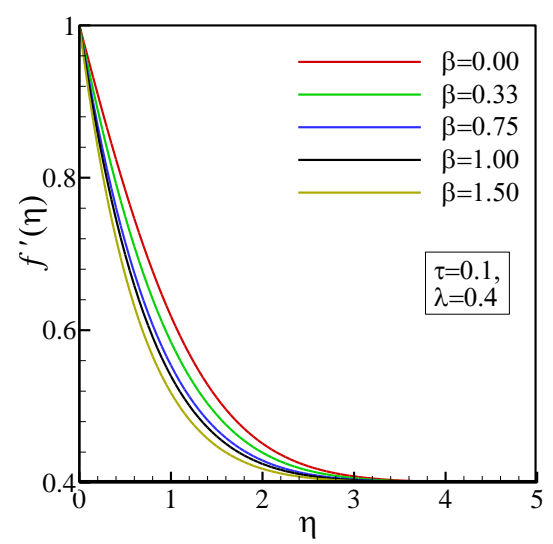

(a)

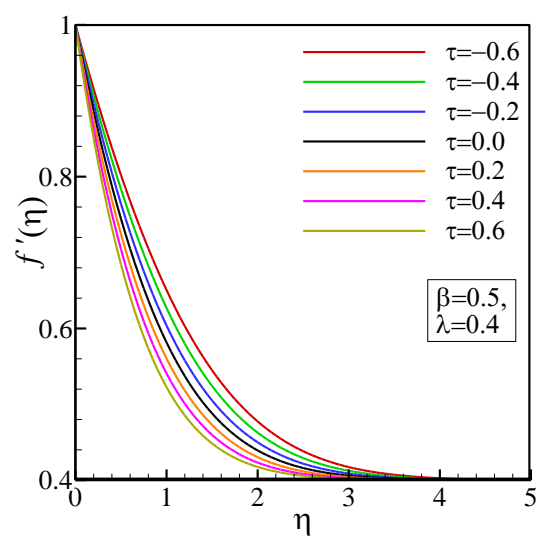

(b)

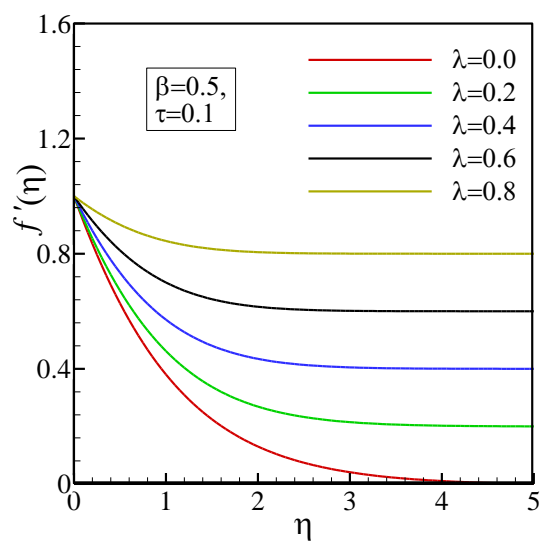

(c)

Fig. 2. Velocity profiles $f^{\prime}(\eta)$ for various values of (a) wedge angle parameter $\beta$,

(b) suction/injection parameter $\tau$, and (c) velocity ratio parameter $\lambda$

number Pr, Eckert number Ec, and temperature jump parameter $\delta$. It is seen in Figs. $3 \mathrm{a}$ and $3 \mathrm{e}$ that the variations of wedge angle parameter $\beta$ or Eckert number Ec do not have much effect on temperature profiles. However, as it is seen in Figs. $3 \mathrm{~b}$ and $3 \mathrm{c}$, the augmentation of suction/injection parameter $\tau$ or velocity ratio parameter $\lambda$ causes the reduction of temperature. In Fig. $3 d$, the increase of Prandtl number $\operatorname{Pr}$ is observed to decrease the temperature, particularly further from the wedge surface inside the boundary layer. Also, if the temperature jump parameter $\delta$ is increased, the temperature shows a high reduction, especially in the vicinity of the wedge surface (i.e. $\eta=0$ ), as it can be seen in Fig. 3f.

Concentration profiles $\phi(\eta)$ for various values of wedge angle parameter $\beta$, suction/injection parameter $\tau$, velocity ratio parameter $\lambda$, Schmidt number Sc, and reaction rate parameter $\gamma$ are illustrated in Fig. 4. The values of concentration $\phi(\eta)$ do not show considerable variation when the wedge angle parameter $\beta$ is altered, as it is seen in Fig. 4a. Nevertheless, as Figs. $4 \mathrm{~b}$ and $4 \mathrm{c}$ show, boosting the values of 


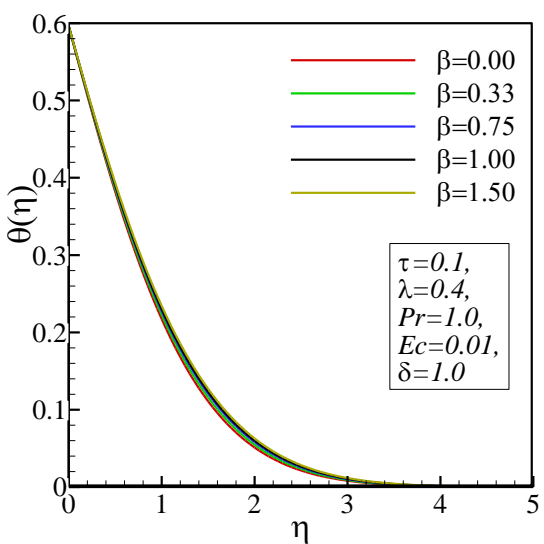

(a)

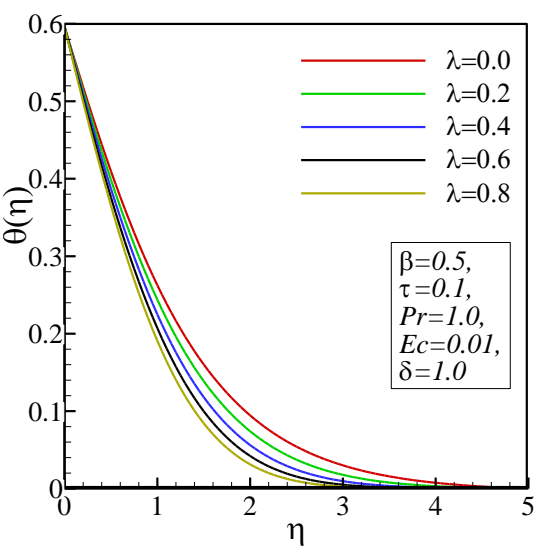

(c)

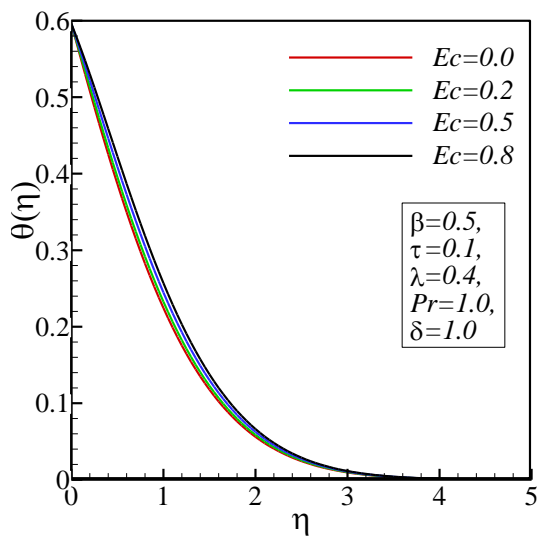

(e)

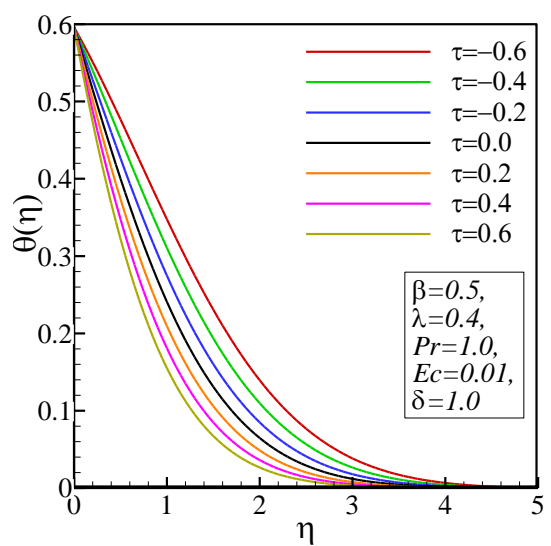

(b)

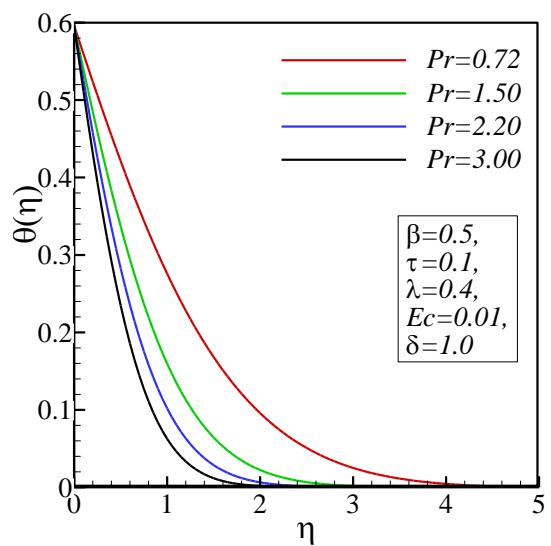

(d)

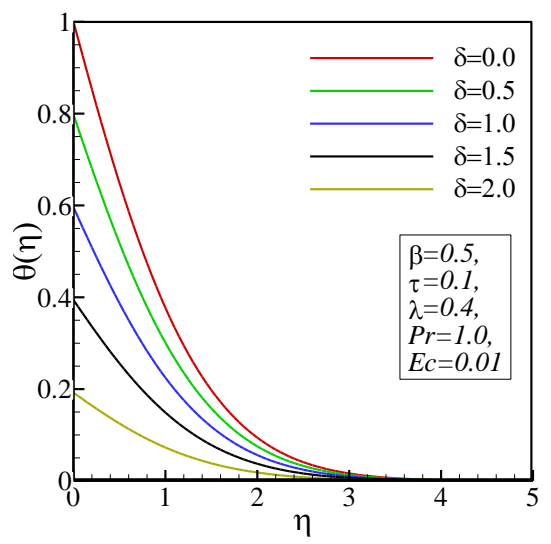

(f)

Fig. 3. Temperature profiles for various values of (a) wedge angle parameter $\beta$, (b) suction/injection parameter $\tau$, (c) velocity ratio parameter $\lambda$, (d) Prandtl number Pr, (e) Eckert number Ec, and (f) temperature jump parameter $\delta$ 


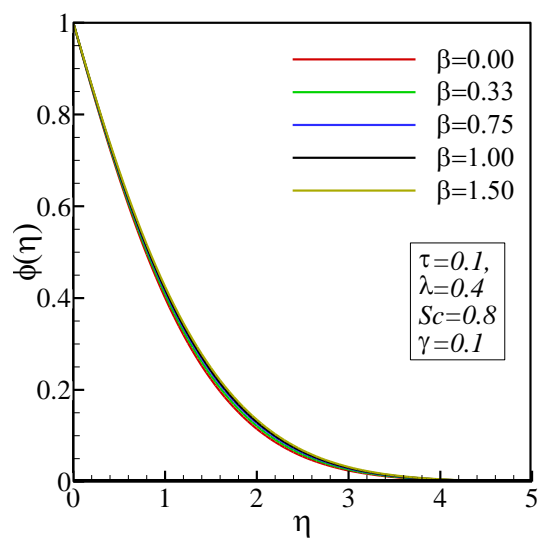

(a)

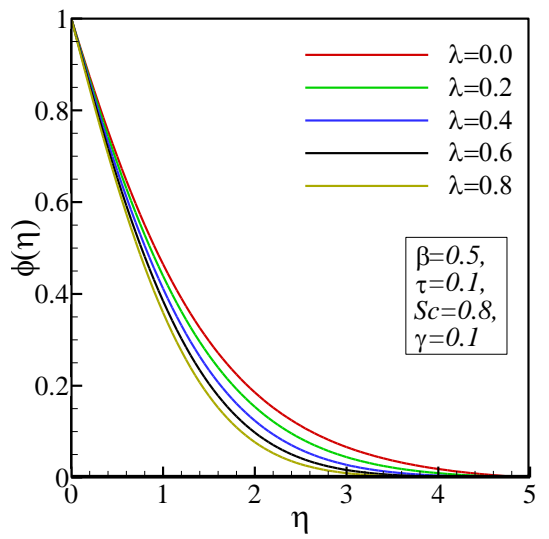

(c)

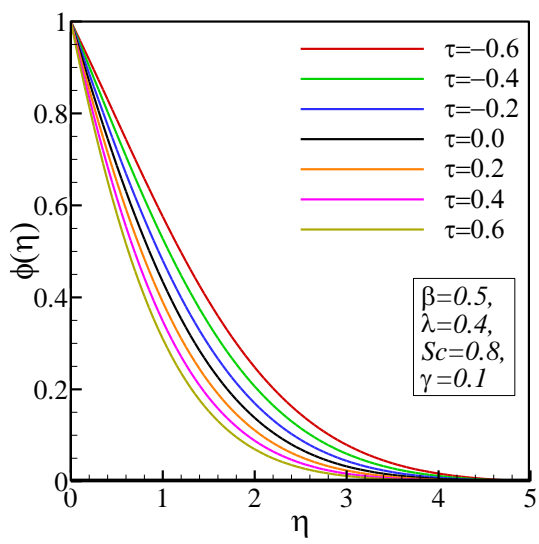

(b)

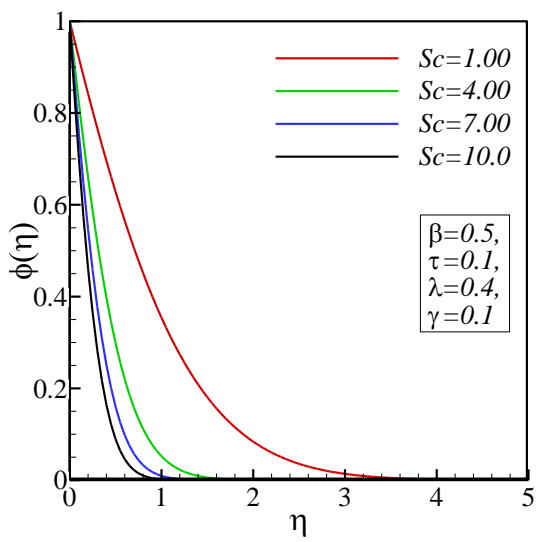

(d)

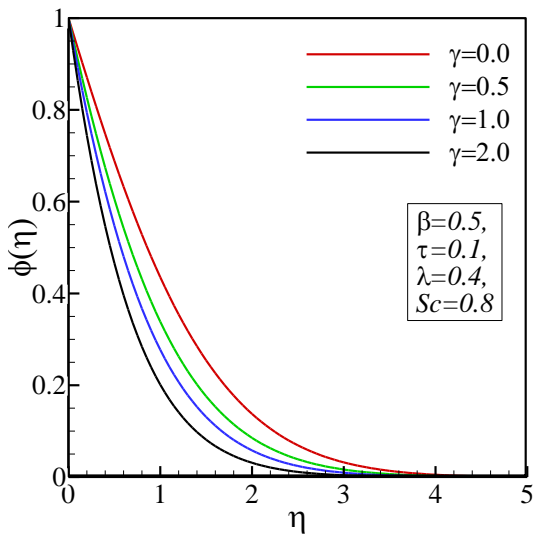

(e)

Fig. 4. Concentration profiles $\phi(\eta)$ for various values of (a) wedge angle parameter $\beta$, (b) suction/injection parameter $\tau$, (c) velocity ratio parameter $\lambda$, (d) Schmidt number Sc, and (e) reaction rate parameter $\gamma$ 
suction/injection parameter $\tau$ and/or velocity ratio parameter $\lambda$ slightly diminishes the concentration values. By the raise of Schmidt number Sc, the concentration is seen in Fig. 4d to have a very steep decrease far from the wedge surface. Also, due to Fig. $4 \mathrm{e}$, the augmentation of reaction rate parameter is observed to reduce the concentration values.

Figs. 5 and 6 show entropy generation number profiles $N_{s}(\eta)$ for various values of wedge angle parameter $\beta$, suction/injection parameter $\tau$, velocity ratio parameter $\lambda$, Prandtl number Pr, Eckert number Ec, temperature jump parameter $\delta$, Schmidt number Sc, reaction rate parameter $\gamma$, Reynolds number Re, dimensionless Brinkman group $\operatorname{Br} \Omega^{-1}$, dimensionless constant parameter $\varepsilon$, and dimensionless concentration difference $\Sigma \Omega^{-1}$. As it is observed in Fig. 5a, the entropy generation number $N_{s}(\eta)$ only indicates a slight increase on the surface of wedge by an augmentation in the wedge angle parameter $\beta$. Due to Fig. $5 \mathrm{~b}$, the increase of the suction/injection parameter $\tau$ causes the entropy generation number to heighten, particularly in the wedge surface neighbourhood. In the locality of wedge surface, the increase of velocity ratio parameter $\lambda$ could lower the entropy generation number, as it is viewed in Fig. 5c. As Fig. 5d illustrates, the increase of Prandtl number Pr could have a relatively high increasing effect on the entropy generation number. The boost of Eckert number Ec causes the entropy generation number to slightly decrease, just on the wedge surface, as it is observable in Fig. 5e. According to Fig. $5 \mathrm{f}$, the increase of temperature jump parameter $\delta$ could highly diminish the entropy generation number profiles, all along inside the boundary layer. The variations of Schmidt number Sc or reaction rate parameter $\gamma$ do not noticeably affect the entropy generation number, as it seen in Figs. 6a and 6b. According to Fig. 6c, an increase in the Reynolds number Re extremely augments the entropy generation number. Also, the increase of the dimensionless Brinkman group $\operatorname{Br} \Omega^{-1}$ could cause the increase of the entropy generation number $N_{s}(\eta)$, due to Fig. 6d. Based on Figs. 6e and 6f, a boosting of the dimensionless constant parameter $\varepsilon$ or the dimensionless concentration difference $\Sigma \Omega^{-1}$ augments the entropy generation number.

In Figs. 7 and 8 , the Bejan number profiles $\operatorname{Be}(\eta)$ for various values of the wedge angle parameter $\beta$, suction/injection parameter $\tau$, velocity ratio parameter $\lambda$, Prandtl number Pr, Eckert number Ec, temperature jump parameter $\delta$, Schmidt number Sc, reaction rate parameter $\gamma$, Reynolds number Re, dimensionless Brinkman group $\mathrm{Br} \Omega^{-1}$, dimensionless constant parameter $\varepsilon$, and dimensionless concentration difference $\Sigma \Omega^{-1}$ are shown. As it is seen in Fig. 7a, sufficiently far from the wedge surface, the Bejan number increases with an increase in the wedge angle parameter $\beta$. According to Fig. $7 \mathrm{~b}$, the increase of the suction/injection parameter $\tau$ causes the Bejan number Be to decrease, in distances adequately far from the wedge. The increase of velocity ratio parameter $\lambda$ is seen in Fig. $7 \mathrm{c}$ to highly increase the Bejan number Be. As it is observable in Fig. 7d, the Prandtl number Pr increase could reduce the Bejan number. The augmentation of Eckert number Ec results in a slight increase of Bejan number, as it is seen in Fig. 7e. The increase 


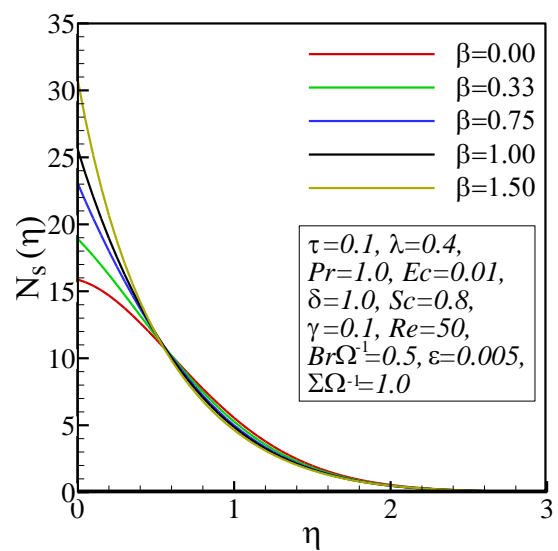

(a)

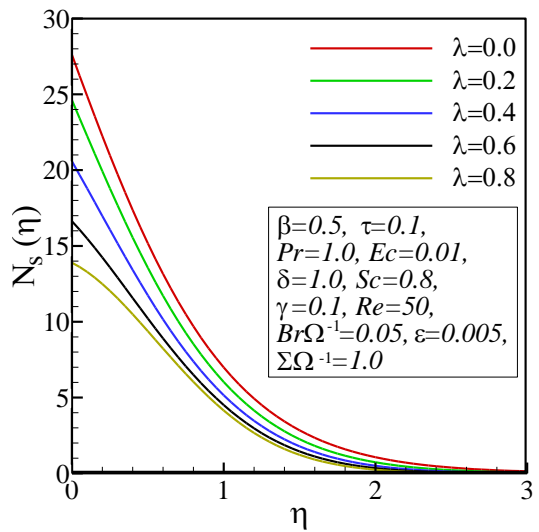

(c)

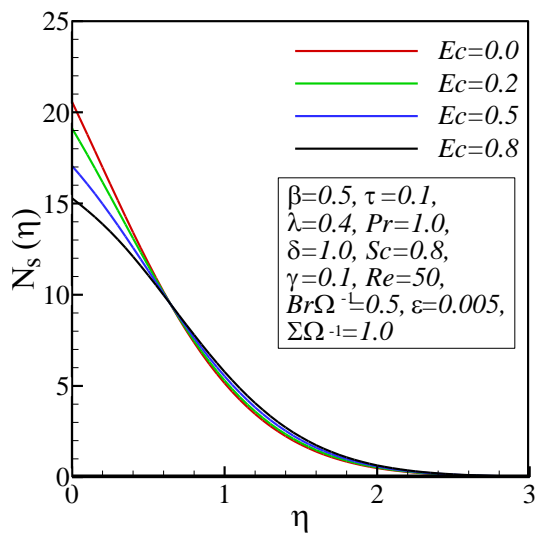

(e)

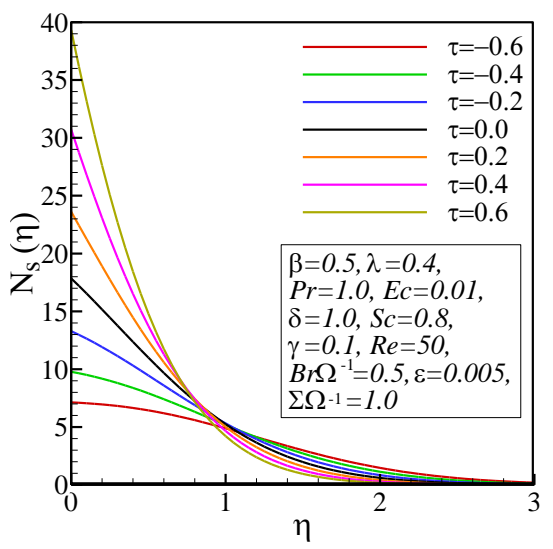

(b)

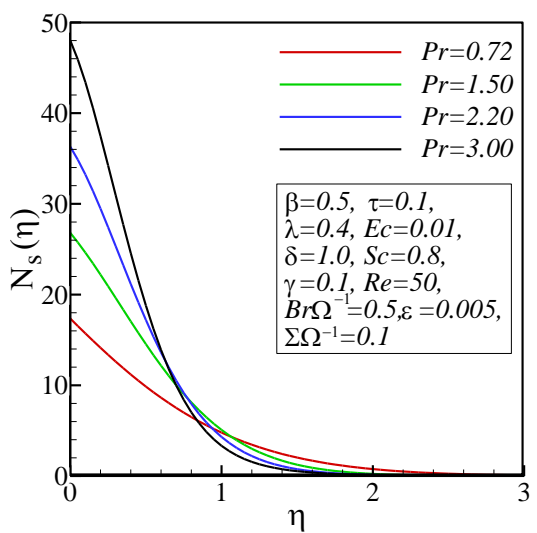

(d)

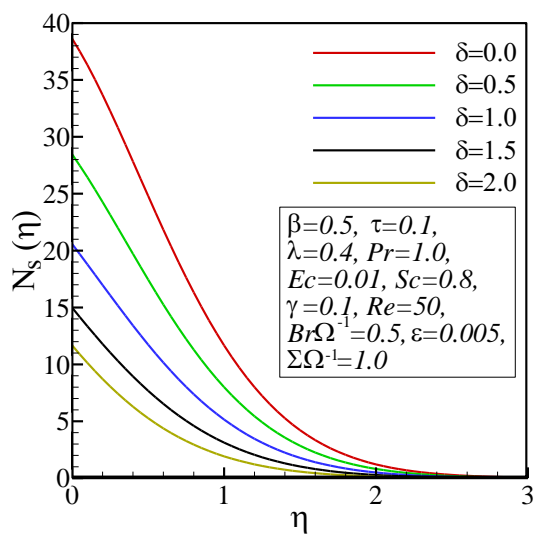

(f)

Fig. 5. Entropy generation number profiles $N_{S}(\eta)$ for various values of (a) wedge angle parameter $\beta$, (b) suction/injection parameter $\tau$, (c) velocity ratio parameter $\lambda$, (d) Prandtl number Pr, (e) Eckert number Ec, (f) temperature jump parameter $\delta$ 


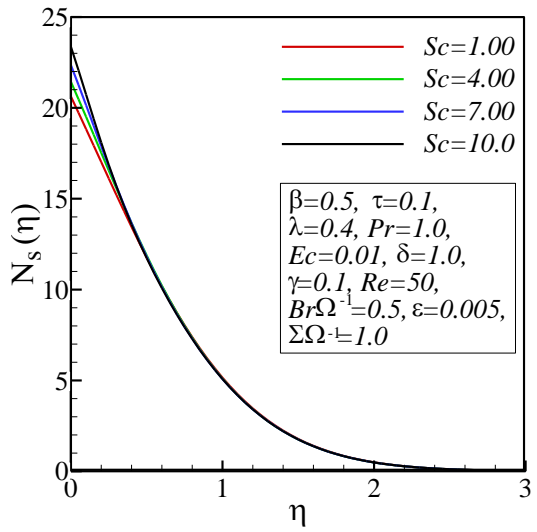

(a)

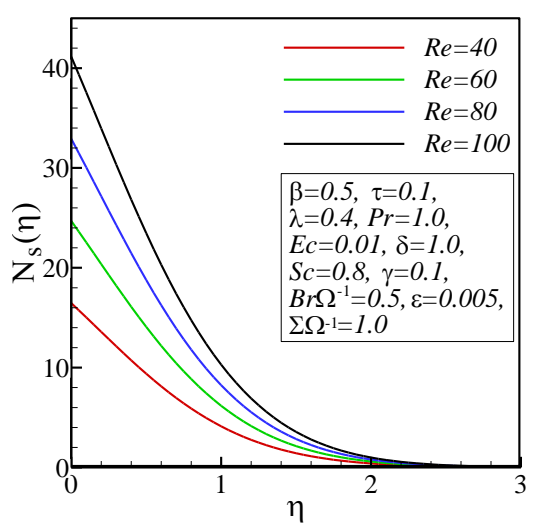

(c)

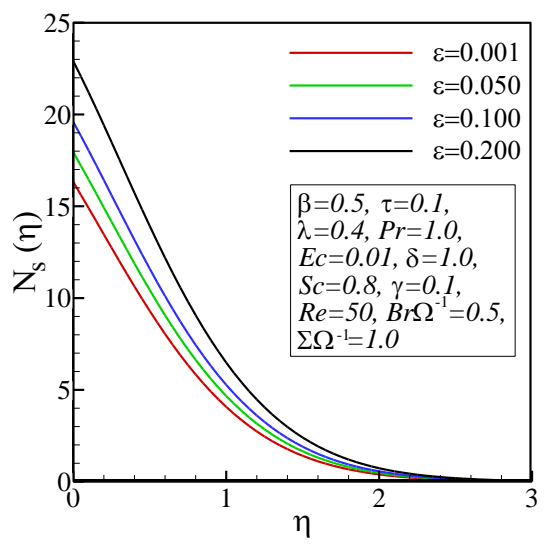

(e)

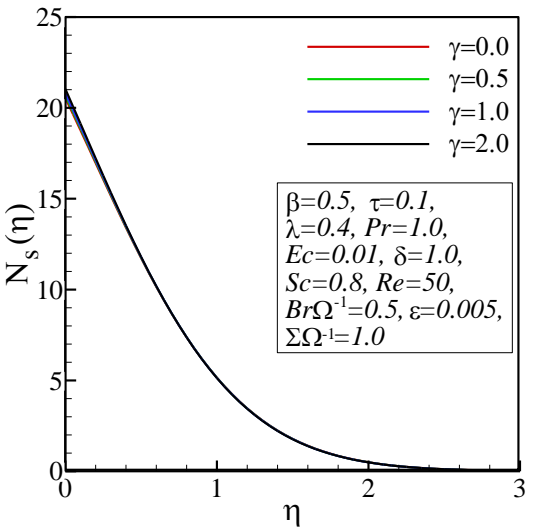

(b)

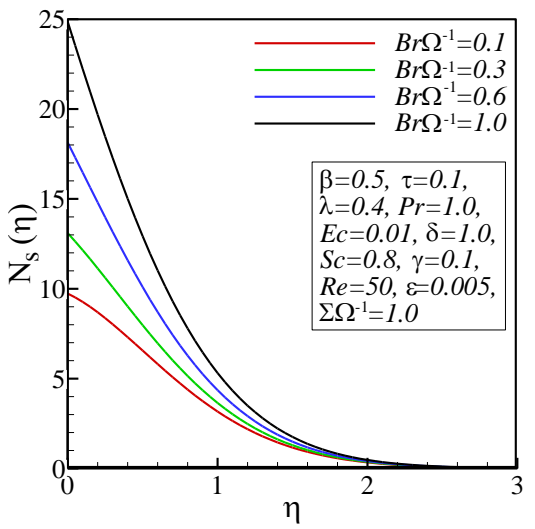

(d)

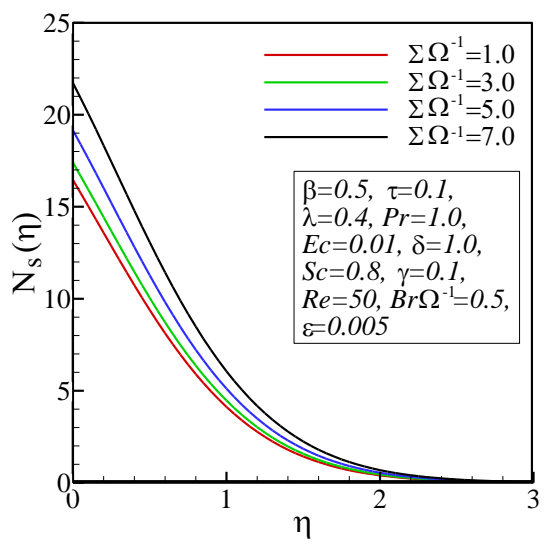

(f)

Fig. 6. Entropy generation number profiles $N_{S}(\eta)$ for various values of (a) Schmidt number Sc, (b) reaction rate parameter $\gamma$, (c) Reynolds number Re, (d) dimensionless Brinkman group $\operatorname{Br} \Omega^{-1}$, (e) dimensionless constant parameter $\varepsilon$, and (f) dimensionless concentration difference $\Sigma \Omega^{-1}$ 


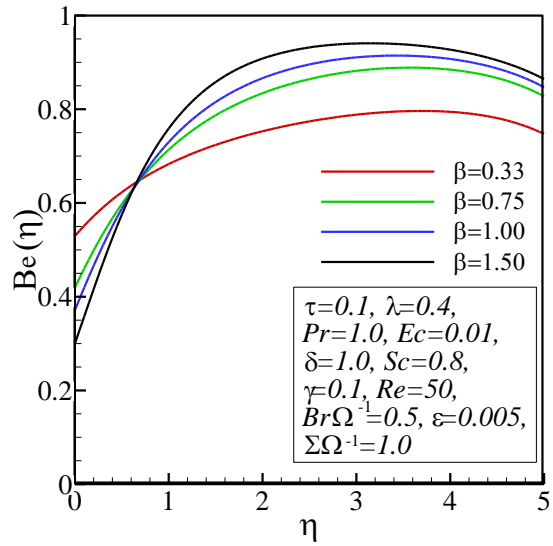

(a)

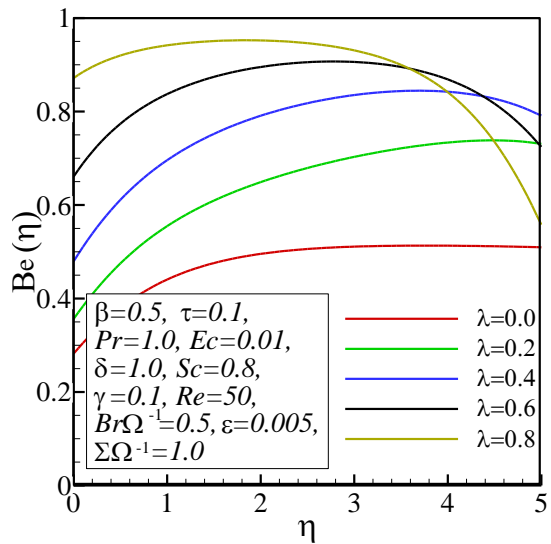

(c)

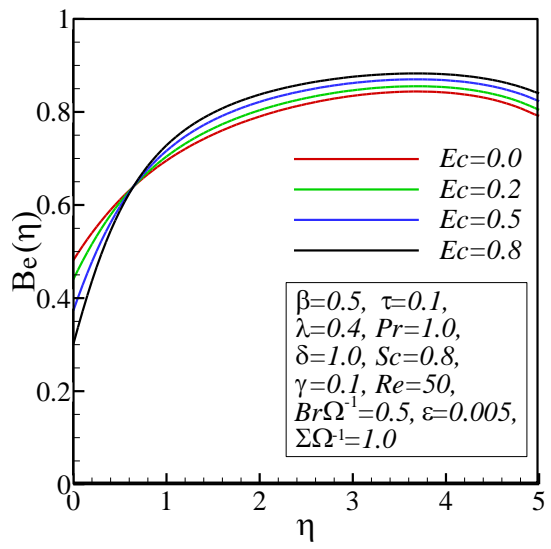

(e)

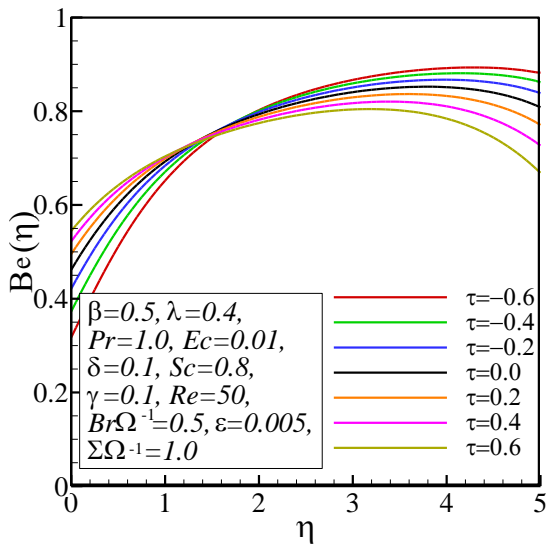

(b)

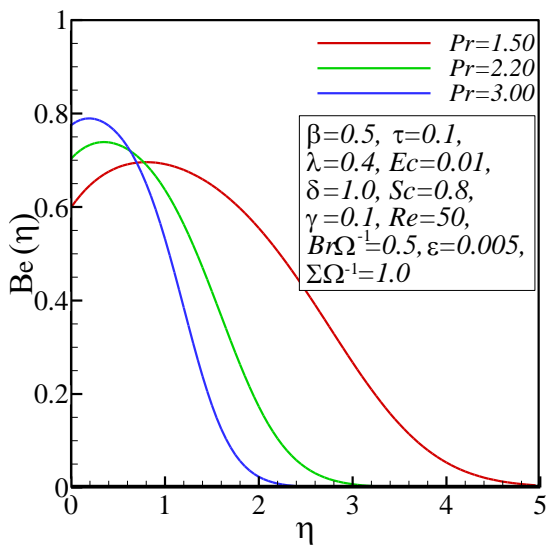

(d)

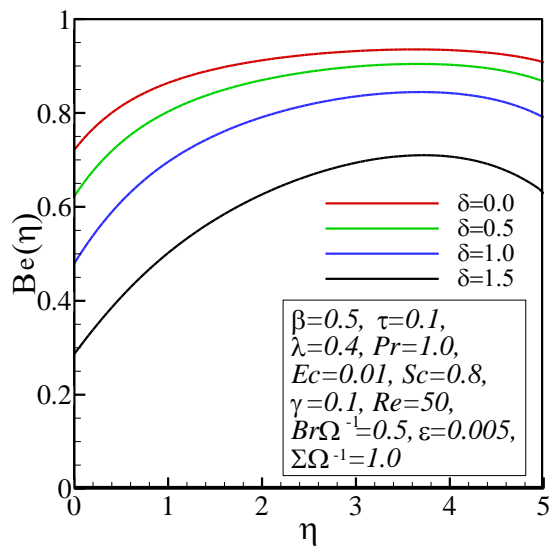

(f)

Fig. 7. Bejan number profiles $\operatorname{Be}(\eta)$ for various values of (a) wedge angle parameter $\beta$, (b) suction/injection parameter $\tau$, (c) velocity ratio parameter $\lambda$, (d) Prandtl number Pr, (e) Eckert number Ec, (f) temperature jump parameter $\delta$ 


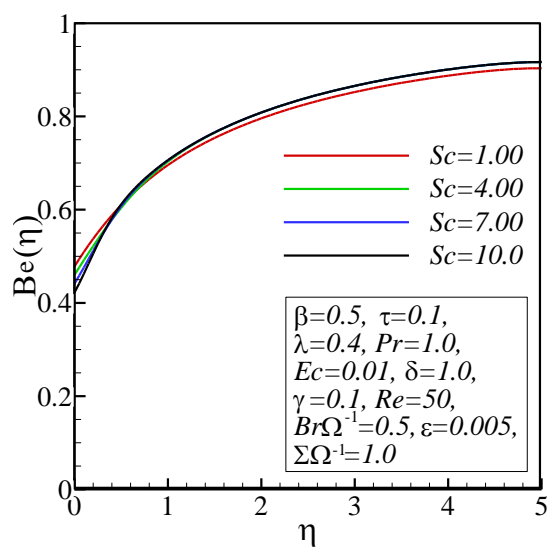

(a)

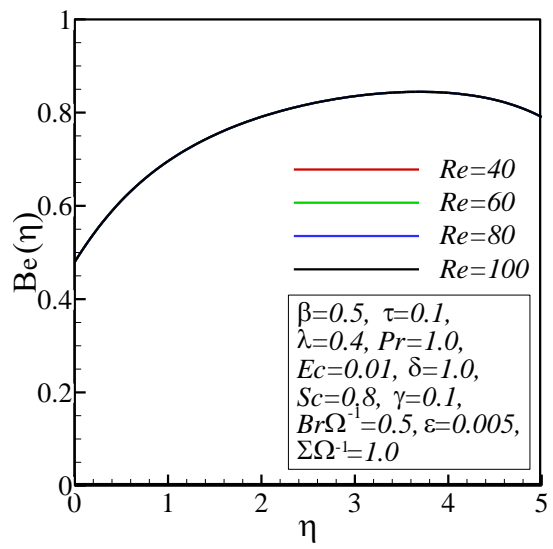

(c)

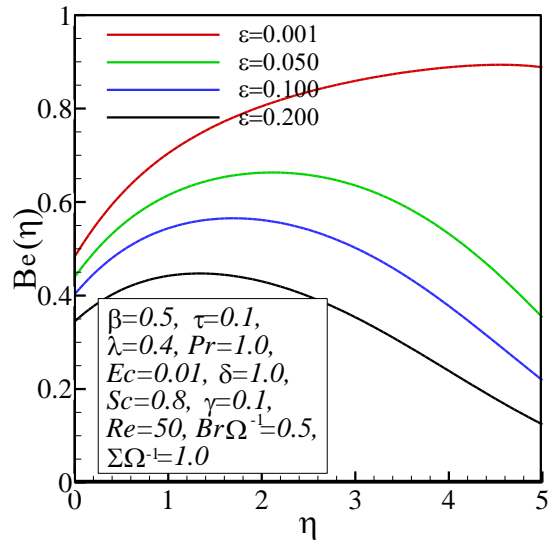

(e)

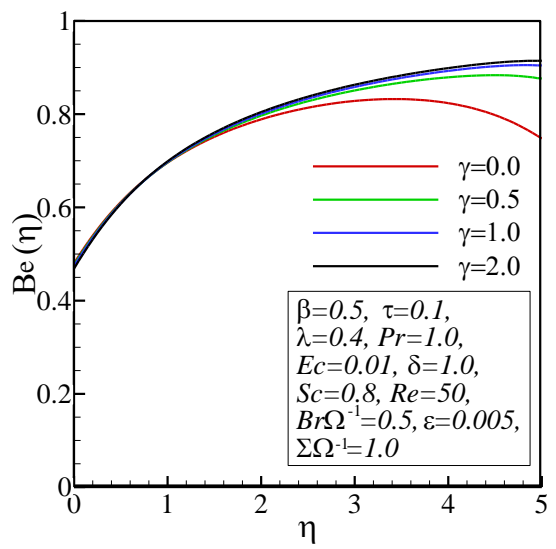

(b)

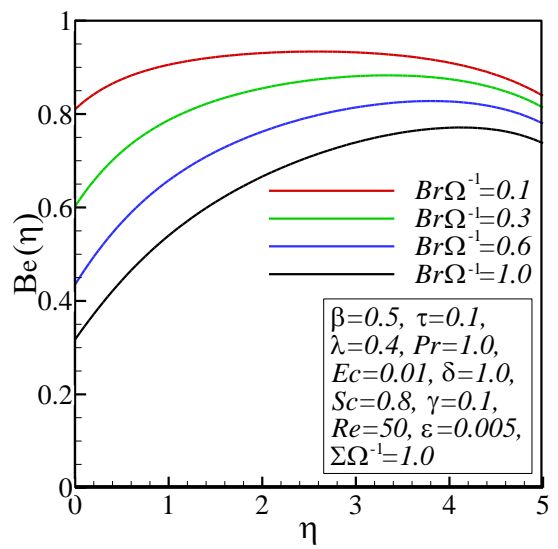

(d)

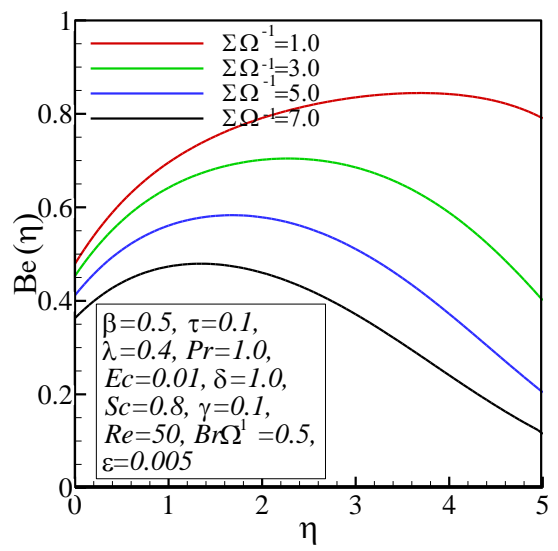

(f)

Fig. 8. Bejan number profiles $\operatorname{Be}(\eta)$ for various values of (a) Schmidt number Sc, (b) reaction rate parameter $\gamma$, (c) Reynolds number Re, (d) dimensionless Brinkman group $\operatorname{Br} \Omega^{-1}$, (e) dimensionless constant parameter $\varepsilon$, and (f) dimensionless concentration difference $\Sigma \Omega^{-1}$ 
of temperature jump parameter $\delta$ can considerably cause the reduction of the Bejan number, as it is observed in Fig. 7f. Due to Figs. 8a and 8b, the alterations in Schmidt number Sc or reaction rate parameter $\gamma$ do not have noticeable effect on Bejan number. Also, based on Fig. 8c, the Reynolds number variations do not have any effects on the Bejan number profiles. It is seen in Fig. 8d that the Bejan number greatly decreases with an increase in the dimensionless Brinkman group $\operatorname{Br} \Omega^{-1}$, especially in the close proximity of the wedge surface. As it is observed in Figs. 8e and 8f, the influences of the dimensionless constant parameter $\varepsilon$ and the dimensionless concentration difference $\Sigma \Omega^{-1}$ on Bejan number are somewhat similar, such that the Bejan number decreases with increases of $\varepsilon$ and/or $\Sigma \Omega^{-1}$, particularly further from the wedge surface.

\section{Conclusions}

Entropy generation analysis for the steady two dimensional laminar forced convection flow, heat and mass transfer of an incompressible fluid over a stretching permeable wedge in presence of viscous dissipation, temperature jump, and chemical reaction is investigated. The governing boundary layer equations are transformed using suitable similarity transformations to three nonlinear coupled ODEs, which are then solved by using a Keller's box technique. The effects of various controlling parameters on the velocity, temperature, concentration, entropy generation number, and Bejan number are analyzed. The results obtained are as follows:

1. The dimensionless velocity $f^{\prime}(\eta)$ decreases by an increase in the wedge angle parameter $\beta$, while the increase of the velocity ratio parameter $\lambda$ causes the dimensionless velocity to boost.

2. The increase of both the velocity ratio parameter $\lambda$ and the temperature jump parameter $\delta$ results in the reduction of the dimensionless temperature $\theta(\eta)$.

3. The dimensionless concentration $\phi(\eta)$ diminishes by an increase in velocity ratio parameter $\lambda$. Also, the augmentation of Schmidt number Sc and/or reaction rate parameter $\gamma$ decreases the concentration.

4. The entropy generation number $N_{s}(\eta)$ slightly increases by an increase in the wedge angle parameter $\beta$. However, the entropy generation number diminishes by the increases of velocity ratio parameter $\lambda$ or temperature jump parameter $\delta$, especially further from the wedge surface. Also, with the increase of the Reynolds number Re and/or the dimensionless Brinkman group $\operatorname{Br} \Omega^{-1}$, the $N_{s}(\eta)$ shows a great augmentation particularly close to the wedge surface.

5. The Bejan number $\operatorname{Be}(\eta)$ boosts by the increase of the wedge angle parameter $\beta$ or velocity ratio parameter $\lambda$, while the rise of temperature jump parameter $\delta$ decreases the Bejan number. Also, with the increase of the dimensionless constant parameter $\varepsilon$ and/or the dimensionless concentration difference $\Sigma \Omega^{-1}$, the $\operatorname{Be}(\eta)$ highly reduces. 
Manuscript received by Editorial Board, August 17, 2015;

final version, July 07, 2016.

\section{References}

[1] V. Nagendramma,K. Sreelakshmi and G. Sarojamma. MHD heat and mass transfer flow over a stretching wedge with convective boundary condition and thermophoresis. Procedia Engineering, 127:963-969, 2015.

[2] A.J. Chamkha, M. Mujtaba M, A. Quadri and C. Issa C. Thermal radiation effects on MHD forced convection flow adjacent to a non-isothermal wedge in the presence of a heat source or sink. Heat and Mass Transfer, 39(4):305-312, 2003.

[3] D. Pal and H. Mondal. Influence of temperature-dependent viscosity and thermal radiation on MHD forced convection over a non-isothermal wedge. Applied Mathematics and Computation, 212(1):194-208, 2009.

[4] L. Zheng, J. Niu, X. Zhang and Y. Gao. MHD flow and heat transfer over a porous shrinking surface with velocity slip and temperature jump. Mathematical and Computer Modelling, 56(56):133-144, 2012.

[5] A.T.M.M. Rahman, M.S. Alam and M.K. Chowdhury. Thermophoresis particle deposition on unsteady two-dimensional forced convective heat and mass transfer flow along a wedge with variable viscosity and variable Prandtl number. International Communications in Heat and Mass Transfer, 39(4):541-550, 2012.

[6] H. Bararnia, E. Ghasemi, S. Soleimani, A.R. Ghotbi and D.D. Ganji. Solution of the FalknerSkan wedge flow by HPM-Pade method. Advances in Engineering Software, 43(1):44-52, 2012.

[7] I. Muhaimin, R. Kandasamy, A.B. Khamis and R. Roslan. Effect of thermophoresis particle deposition and chemical reaction on unsteady MHD mixed convective flow over a porous wedge in the presence of temperature-dependent viscosity. Nuclear Engineering and Design, 261:95-106, 2013.

[8] A.T.M.M. Rahman, M.S. Alam, M.A. Alim and M.K. Chowdhury. Unsteady MHD forced convective heat and mass transfer flow along a wedge with variable electric conductivity and thermophoresis. Procedia Engineering, 56:531-537, 2013.

[9] K.V. Prasad, P.S. Datti and K. Vajravelu. MHD mixed convection flow over a permeable nonisothermal wedge. Journal of King Saud University - Science, 25(4):313-324, 2013.

[10] I. Muhaimin, R. Kandasamy, A.B. Khamis and R. Rozaini. Influence of thermophoresis particle deposition and chemical reaction on unsteady non-Darcy MHD mixed convective flow over a porous wedge in the presence of temperature-dependent viscosity. Journal of Mechanical Science and Technology, 27(5):1545-1555, 2013.

[11] D. Pal and H. Mondal. Influence of thermophoresis and Soret-Dufour on magneto-hydrodynamic heat and mass transfer over a non-isothermal wedge with thermal radiation and Ohmic dissipation. Journal of Magnetism and Magnetic Materials, 331:250-255, 2013.

[12] M. Ganapathirao, R. Ravindran and I. Pop. Non-uniform slot suction (injection) on an unsteady mixed convection flow over a wedge with chemical reaction and heat generation or absorption. International Journal of Heat and Mass Transfer, 67:1054-1061, 2013.

[13] M.M. Rahman, M.A. Al-Lawatia, I.A. Eltayeb and N. Al-Salti. Hydromagnetic slip flow of water based nanofluids past a wedge with convective surface in the presence of heat generation (or) absorption. International Journal of Thermal Sciences, 57:172-182., 2012.

[14] R. Kandasamy, I. Muhaimin, A.B. Khamis and R.B Roslan. Unsteady Hiemenz flow of Cunanofluid over a porous wedge in the presence of thermal stratification due to solar energy radiation: Lie group transformation. International Journal of Thermal Sciences, 65:196-205, 2013. 
[15] L. Zheng, C. Zhang, X. Zhang and J. Zhang. Flow and radiation heat transfer of a nanofluid over a stretching sheet with velocity slip and temperature jump in porous medium. Journal of the Franklin Institute, 350(5):990-1007, 2013.

[16] R. Kandasamy, I. Muhaimin and A.K. Rosmila. The performance evaluation of unsteady MHD non-Darcy nanofluid flow over a porous wedge due to renewable (solar) energy. Renewable Energy, 64:1-9, 2014.

[17] S. Aiboud and S. Saouli. Entropy analysis for viscoelastic magnetohydrodynamic flow over a stretching surface. International Journal of Non-Linear Mechanics, 45(5):482-489, 2010.

[18] O.D. Makinde O.D.: Entropy analysis for MHD boundary layer flow and heat transfer over a flat plate with a convective surface boundary condition. International Journal of Exergy, 10(2):142-154, 2012.

[19] F. Hedayati, A. Malvandi and D.D. Ganji. Second-law analysis of fluid flow over an isothermal moving wedge. Alexandria Engineering Journal, 53(1):1-9, 2014.

[20] N. Dalir. Numerical study of entropy generation for forced convection flow and heat transfer of a Jeffrey fluid over a stretching sheet. Alexandria Engineering Journal, 53(4):769-778, 2014.

[21] N. Dalir, M. Dehsara and S.S. Nourazar. Entropy analysis for magnetohydrodynamic flow and heat transfer of a Jeffrey nanofluid over a stretching sheet. Energy, 79:351-362, 2015.

[22] M.S. Alam, M. Asiya-Khatun, M.M. Rahman and K. Vajravelu. Effects of variable fluid properties and thermophoresis on unsteady forced convective boundary layer flow along a permeable stretching/ shrinking wedge with variable Parndtl and Schmidt numbers. International Journal of Mechanical Sciences, 105:191-205, 2016.

[23] J.Y. San, W.M. Worek and Z. Lavan. Entropy generation in convective heat transfer and isothermal convective mass transfer. Journal of Heat Transfer, 109(3):647-652, 1987.

[24] M. Magherbi, H. Abbassi, N. Hidouriand A. Ben-Brahim. Second law analysis in convective heat and mass transfer. Entropy, 8(1):1-17, 2006.

[25] Noghrehabadi A., Saffarian M.R., Pourrajab R., Ghalambaz M.: Entropy analysis for nanofluid flow over a stretching sheet in the presence of heat generation/absorption and partial slip. Journal of Mechanical Science and Technology, 2013, Vol. 27, No. 3, pp.927-937.

[26] M.Z. Salleh, R. Nazar, N.M. Arifin and I. Pop. Numerical solutions of forced convection boundary layer flow on a horizontal circular cylinder with Newtonian heating. Malaysian Journal of Mathematical Sciences, 5(2):161-184, 2011.

[27] W. Ibrahim, B. Shankar and M.M. Nandeppanavar. MHD stagnation point flow and heat transfer due to nanofluid towards a stretching sheet. International Journal of Heat and Mass Transfer, 56(1-2):1-9, 2013.

[28] B. Jalilpour, S. Jafarmadar, D.D. Ganji, A.B. Shotorban and H.Taghavifar. Heat generation/ absorption on MHD stagnation flow of nanofluid towards a porous stretching sheet with prescribed surface heat flux. Journal of Molecular Liquids, 195:194-204, 2014.

Analiza produkcji entropii oraz transportu ciepła i masy w przepływie wzdłuż przepuszczalnego klina z uwzględnieniem skoku temperatury i reakcji chemicznych

Streszczenie

W pracy przedstawiono analizę numeryczna procesu produkcji entropi oraz transportu ciepła i masy w stacjonarnym, dwuwymiarowym przepływie konwekcyjnym cieczy lekkiej wzdłuż porowatego klina o nieliniowo zmiennym kącie rozwarcia. W analizie rozważono efekty związane z dyssypacją lepkościową, skokiem temperatury reakcjami chemicznymi pierwszego rzędu. Równania różniczkowe opisujące transport masy, pędu, energii i stężeń reagentów w warstwie przyściennej zostały przekształcone za pomocą odpowiednich transformacji do układu trzech równań różniczkowych zwyczajnych. Trzymany układ został rozwiązany numerycznie za pomocą algorytmu typu 
box zaproponowanego przez Kellera. W pracy zbadano i przedstawiono w formie graficznej wpływ parametrów takich, jak kąt rozwarcia klina, intensywność transpiracji przez ścianę klina, liczby Prandtla, Eckerta i Schmidta, wielkość skoku temperatury i szybkość reakcji chemicznych na pola prędkości, temperatury i stężenia reagentów, produkcję entropii i liczbę Bejana. Otrzymane wyniki pokazują, że współczynnik produkcji entropii rośnie wraz z powiększaniem kąta klina i maleje wraz powiększaniem stosunku prędkości. W celu walidacji otrzymanych rezultatów, porównano je z wynikami innych dostępnych w literaturze badań i stwierdzono bardzo dobrą zgodność. 